\title{
RISK ANALYSIS USING JOB SAFETY ANALYSIS-FUZZY INTEGRATION FOR SHIP MAINTENANCE OPERATION
}

\author{
Catur Wahyu Nugroho I Trika Pitana* I Bagus Dinariyana
}

\footnotetext{
${ }^{1}$ Dept. of Marine Engineering, Institut Teknologi Sepuluh Nopember, Surabaya, Indonesia
}

\section{Correspondence}

*Trika Pitana, Dept of Marine Engineering, Institut Teknologi Sepuluh Nopember, Surabaya, Indonesia. Email: trika@its.co.id

\section{Present Address}

Gedung Teknik Kelautan, Jl. Teknik Kimia, Kampus ITS Sukolilo, Surabaya 60111, Indonesia

\begin{abstract}
Shipyard is an industry engaged in the maintenance and repair of ships and constructing a new ship. In ship repair operations, there are many activities in this operation. Propeller inspection, blasting, replating, welding, general work, electric work is an activity in ship repair operation. This research proposed a methodology to risk analysis ship maintenance operation, integrating Job Safety Analysis (JSA) with Bayesian Network (BN) and Fuzzy Inferences System (FIS). JSA method is used to find the hazards and the consequences of the maintenance operation. BN is developed for probability calculating of likelihood factors. Meanwhile, the FIS is used as a method to calculate the risk level. The FIS using the Mamdani algorithm based on the expert's knowledge and experience. The integration of three methods is used to complete the risk assessment for replating activities. The proposed method is used to find out the risk level of replating activity on ship maintenance. Based on the result, the proposed model is more accurate, precise, and flexible depending on the basic factor that influences the operation. It would help to reduce the potential accident on the operation. This proposed method could be the other option as a tool to calculate risk assessment in other operations.
\end{abstract}

\section{KEYWORDS:}

Job Safety Analysis, Bayesian Networks, Fuzzy, Replating, Risk Assessment

\section{1 | INTRODUCTION}

The shipyard is an industry that focused on building new ships and ship repair. This is an extremely complex business, highly technical, and requires skilled workers. Shipyards have much hazardous work than other industries, which means a building or ship repair has a complicated task to be performed ${ }^{11}$. The main risk factors for an occupational accident are carelessness of the workers, insufficient safety training and education, unawareness of costs of accidents, erroneous series of human operations, 
TABLE 1 Likelihood factor levels.

\begin{tabular}{|c|c|c|c|c|}
\hline Level & Criteria & $\begin{array}{l}\text { Probability } \\
\text { Range }\end{array}$ & Qualitative & $\begin{array}{c}\text { Semi } \\
\text { Qualitative }\end{array}$ \\
\hline 1 & $\begin{array}{l}\text { Very Small / } \\
\text { Rare }\end{array}$ & $\mathrm{x}<10 \%$ & $\begin{array}{l}\text { events are possible only in very } \\
\text { extraordinary situations }\end{array}$ & less than once in 5 years \\
\hline 2 & Small & $10 \% \leq x<40 \%$ & $\begin{array}{l}\text { events are possible in special } \\
\text { situations }\end{array}$ & at least once a year \\
\hline 3 & Moderate & $40 \% \leq x<70 \%$ & $\begin{array}{l}\text { occurrence is possible in most } \\
\text { situations }\end{array}$ & at least once in 6 months \\
\hline 4 & High & $70 \% \leq x<90 \%$ & $\begin{array}{l}\text { often happens, it is expected to } \\
\text { appear in the most common } \\
\text { circumstances }\end{array}$ & at least once in 3 months \\
\hline 5 & Very High & $90 \% \leq x \leq 100 \%$ & $\begin{array}{l}\text { very often, often appears in a } \\
\text { period and dominant }\end{array}$ & $\begin{array}{l}\text { more than one time per } \\
\text { month }\end{array}$ \\
\hline
\end{tabular}

TABLE 2 Consequences factor levels.

\begin{tabular}{|c|c|c|c|c|}
\hline Level & Criteria & Financial & $\begin{array}{c}\text { Budget } \\
\text { Deviation }\end{array}$ & $\begin{array}{c}\text { OHS } \\
\text { Qualitative }\end{array}$ \\
\hline 1 & Very low & financial loss up to & budget deviation & occurrence of illness or accident that can \\
\hline 2 & Minor & $\begin{array}{l}\text { the financial loss of } \\
100 \text { million rupiah } \\
-1 \text { billion rupiah }\end{array}$ & $\begin{array}{l}\text { budget deviation } \\
\text { above } 2 \% \text { to } 5 \%\end{array}$ & $\begin{array}{l}\text { occurrence of illness or work accident } \\
\text { that can be overcome by medical action } \\
\text { or treatment }\end{array}$ \\
\hline 3 & Moderate & $\begin{array}{l}1 \text { billion to } 12.5 \\
\text { billion rupiah }\end{array}$ & $\begin{array}{l}\text { budget deviation } \\
\text { above } 5 \% \text { to } 10 \%\end{array}$ & $\begin{array}{l}\text { occurrence of illness or work accident } \\
\text { that can be overcome with medical } \\
\text { assistance or hospitalization }\end{array}$ \\
\hline 4 & Major & $\begin{array}{l}12.5 \text { billion to } 75 \\
\text { billion rupiah }\end{array}$ & $\begin{array}{l}\text { budget deviation } \\
\text { above } 10 \% \text { to } 25 \%\end{array}$ & $\begin{array}{l}\text { occurrence of illness or work accident } \\
\text { and cause death }\end{array}$ \\
\hline 5 & Very High & $>75$ billion rupiah & $\begin{array}{l}\text { budget deviation } \\
\text { above } 25 \%\end{array}$ & $\begin{array}{l}\text { occurrence of illness or work accident } \\
\text { that causes death and threatens the } \\
\text { closure of the company's operations }\end{array}$ \\
\hline
\end{tabular}

and inadequate worksite environment. The shipyards industry in Indonesia has been characterized ${ }^{[2]}$ : capital-intensive, laborintensive, slow yield, low added value, complex value chain, non-competitive, high-risk, low demand, high-tech, requires highly skilled personnel for ship design and fabrication, high import level with a low level of local material content, low experience levels, and long-term delivery. However, the shipyards industry is categorized as high-risk. There are only limited applications of risk management in various activities.

In ship repair operations, there are many activities in this operation. Propeller inspection, blasting, replating, welding, general work, electric work is an activity in ship repair operation. Replating activities is one activity that has much sub-activity or complexity of the work. This activity is complex because it consists of many sub-activities, i.e., plate detection, plate cutting, handling material, grinding the plate, plate welding, and blasting. With this many activities, it can make the replating have more hazards or causes that can impact the maintenance process. The consequences of the hazards or causes would make the replating scheduled not on time, or sometimes it can cause accidents. These consequences happen based on the hazards or causes.

The hazards or causes of replicating activities need to be identified more specifically to reduce or prevent the hazards or causes. Risk analysis is one of the methods that can use to identify the hazards/causes and give information about the risk level. The traditional risk assessment is usually used the likelihood (L) and consequences (C) level to calculate the risk level (RL). Table 1 and Table 2 are used to calculate the traditional risk assessment. It is calculated using Eq. 1.

$$
R L=L \times C
$$

This traditional risk assessment has weaknesses. It cannot be used for flexible likelihood. It cannot calculate the unexpected accident uncertainty value due to the complexity of the replating activities that have more variant hazards/causes and unexpected factors. Another limitation is the output of the traditional method may be inaccurate in real-life problems ${ }^{3}$. So, another method should be used to calculate the risk assessment. 
The research proposed a method that can use an alternative method for risk assessment from the explanation above. The research conducted three methods, i.e., Job Safety Analysis (JSA), Bayesian Networks (BNs), and Fuzzy Inference System (FIS). The integration of three methods is used to complete the risk assessment for replating activities. That is necessary because each method has a purpose or function for risk assessment. So, the result of the proposed method can identify every hazard/cause in more detail, flexibility, and the risk level. This is important because the replating activities need to identify the hazards/causes and which causes need to be prevented. This process would make the ship maintenance on schedule.

Job Safety Analysis (JSA) is a method for identifying, evaluating, and controlling risks in industrial procedures ${ }^{[4}$. The JSA method has proven effective for planning the safest ways and identifying hazards/causes to perform a task ${ }^{[5]}$. Several methods are used to determine the risk ranking in risk analysis than using the Muhlbauer method ${ }^{6}$.

Bayesian network $(\mathrm{BN})$ is used to calculate the probability factor that occurs the hazards and methodology for quantifying risk in industrial. BN has been used to establish a realistic model of the causation probability (failure rate) for grounding and collision analysis 7 . The benefit of using BN for risk analysis shows a correlation between sources of the accident event, considers all feasible accident of failure scenarios and their related consequences, integrative qualitative information with quantitative knowledge on the different abstraction levels $\underline{8}$.

Fuzzy logic is a method used to determine the risk ranking assessment. The fuzzy method in determining risk has advantages over using the hierarchy method 9 [11]. Another advantage is that the fuzzy method is more accurate and precise for assessing the level of risk because it can calculate the uncertainty value and unexpected factors. This paper aims to propose a methodology for risk analysis on ship maintenance, especially replicating activities. The research is using integration JSA combined with BN and Fuzzy methods. JSA is used to perform a risk identification of replating activities, whereas BN calculates the likelihood of each replating hazard/cause. Then, the risk level is calculated using the fuzzy method. The research effort could assist for risk analysis, where the more efficient and effective to identify the potential hazards of operational ship maintenance.

The rest of the paper is organized as follows: Section II presents the information about ship maintenance and risk modeling methods used in this research. Section III discussed the proposed methodology for risk assessment in replating activities and the result of this research. Section IV gives the conclusions for this research and further research to provide the best application.

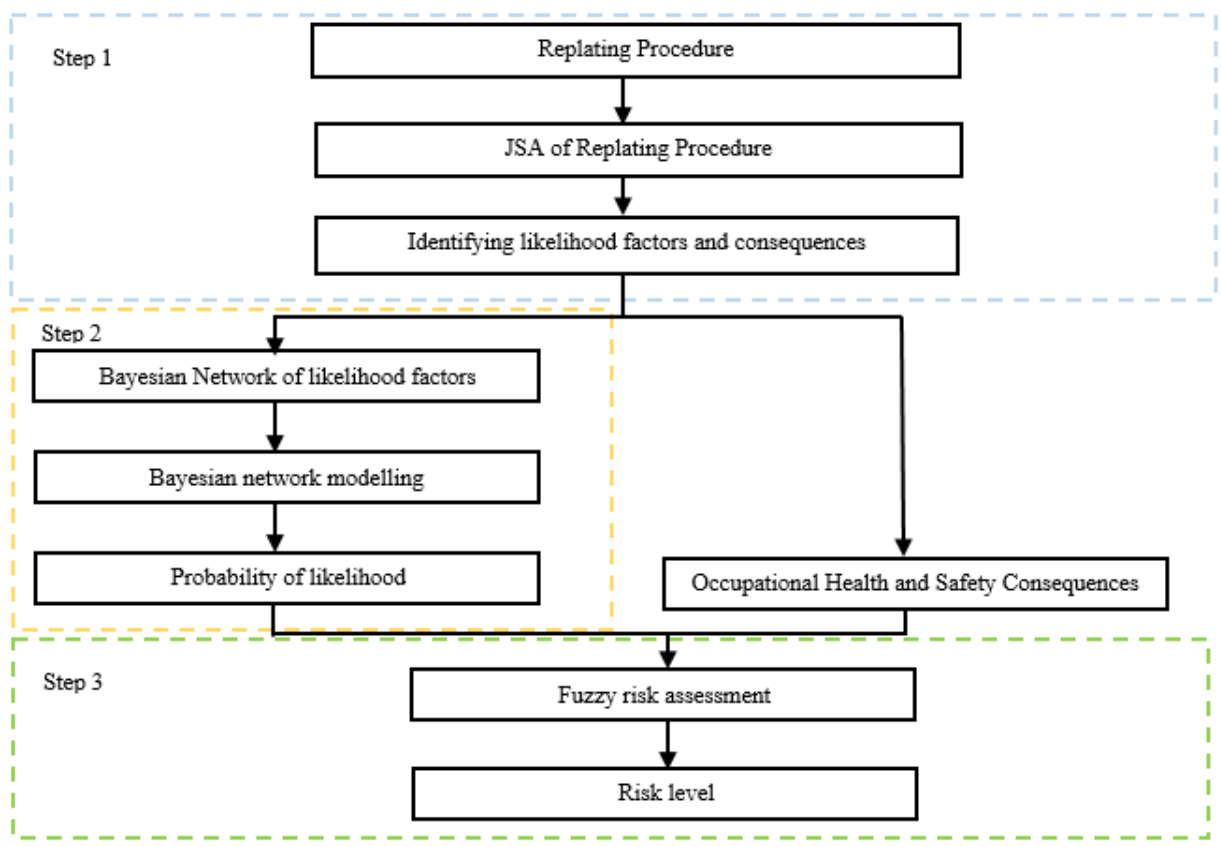

FIGURE 1 Methodology for risk assessment replating activity. 
TABLE 3 Risk matrix.

\begin{tabular}{|c|c|c|c|c|c|c|c|}
\hline \multicolumn{3}{|c|}{ RL } & \multicolumn{5}{|c|}{ Consequences } \\
\hline \multirow{11}{*}{$\begin{array}{l}\overline{8} \\
0 \\
\frac{0}{0} \\
\frac{0}{3} \\
\frac{1}{3}\end{array}$} & Level & Probability & Very Low & Minor & Moderate & Mayor & High \\
\hline & & Range & 1 & 2 & 3 & 4 & 5 \\
\hline & Very High & $90 \%-100 \%$ & Medium & Medium & High & Very High & Very High \\
\hline & High & $70 \%-90 \%$ & Medium & Medium & $\begin{array}{l}\text { IJ } \\
\text { High }\end{array}$ & High & Very High \\
\hline & 4 & & 4 & 8 & 12 & 16 & 20 \\
\hline & Moderate & $40 \%-70 \%$ & Low & Medium & Medium & High & High \\
\hline & 3 & & 3 & 8 & 9 & 12 & 15 \\
\hline & Low & $10 \%-40 \%$ & Low & Medium & Medium & Medium & Medium \\
\hline & 2 & & 2 & 4 & 6 & 8 & 10 \\
\hline & Very Low & $<10 \%$ & Low & Low & Low & Medium & Medium \\
\hline & 1 & & 1 & 2 & 3 & 4 & 5 \\
\hline
\end{tabular}

\section{2 | MATERIAL AND METHOD}

The discussion risk assessment for a ship maintenance operation, especially on replating activity, is presented in Figure 1. The first step is identifying the hazards/causes using Job Safety Analysis (JSA) based on Replating. The second step is modeling the Bayesian Networks and calculating the probability of likelihood. The Last step is risk assessment using a fuzzy inference system.

\section{1 | Job Safety Analysis}

The first step of the proposed method is to determine the replating procedures and the hazards/causes of the activity. Job Safety Analysis is a technique that focuses on job tasks to identify hazards before they occur ${ }^{[12}$. The jobs that require JSA are jobs that have potential fatal factors, frequent injury, and historical accidents, etc. ${ }^{[13]}$. The jobs should be divided into several steps, and hazard identification was conducted for each step $\underset{14]}{ }$.

A JSA table should include the following attributes: sub-activity, hazards, likelihood (L), consequences value of the activities, and the risk level of the hazards (R). The activities were divided into several sub-activities soo the hazards/causes more specific. The hazards/causes of the sub-activities were carried out depending on the hazards/causes. Not only hazards/causes on safety but also the hazards on equipment, workers, and weather would impact these activities.

The traditional risk assessment was calculated on this JSA table. The likelihood and consequences data get from PT. PAL Indonesia (persero). The likelihood value is based on Table 1, and the value of the consequences is based on Table 2. The last step for traditional risk assessment is the calculation of the risk level. Table 3 is used to determine the risk level of the hazards/causes.

\section{2 | Bayesian Network}

Bayesian networks (BN) are probabilistic graphical models capable of modeling the joint probability distribution over a finite set of random variables ${ }^{[15]}$. The structure of the BN is also called the Directed Acrylic Graph (DAG). It represents interactions between nodes, which represent a direct relationship between one variable and another ${ }^{16}$. Research has been carried out on height work to determine the risk of the work using Bayesian networks ${ }^{[17]}$. BN has several advantages, including easy modeling and complex systems analysis, making predictions, multi-variable based calculations, and calculating probabilistic and statistical analysis in the fields of reliability, risk, and maintenance ${ }^{8}$.

Thomas Bayes put forward this theory with the formula:

$$
P(A \mid B)=\frac{P(B \mid A) P(A)}{P(B)}
$$

The Bayesian network uses a simple structure with a node that clarifies as parent nodes of several other nodes 18$]$.

\section{3 | Fuzzy Method}

Fuzzy is a collection of information where the boundary contained in the universe is ambiguous, vague, and otherwise fuzzy 19 . Fuzzy generally has input, process, and output. The fuzzy inference system (FIS) is comprised of the following step [20], i.e.: 


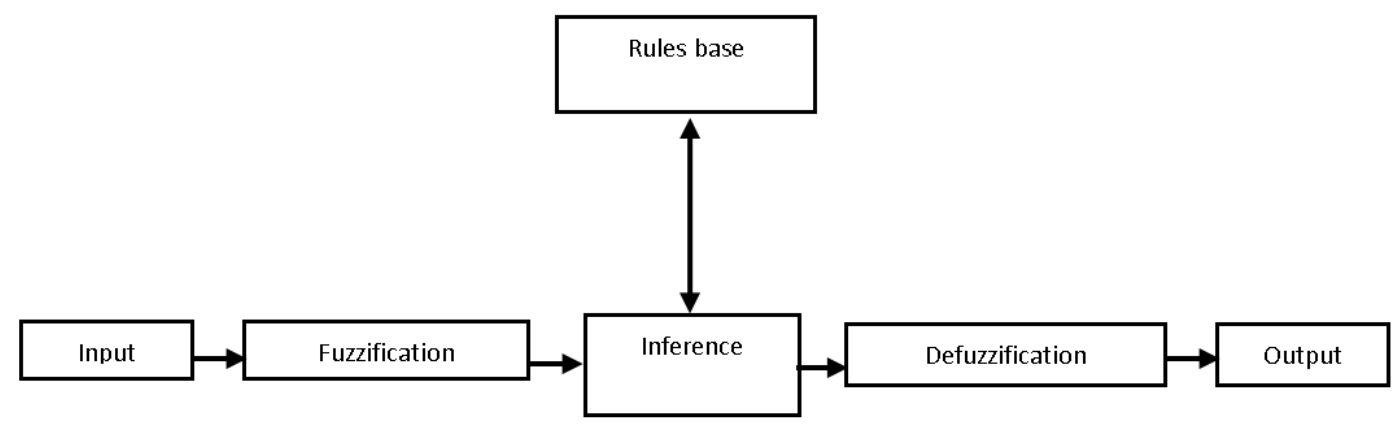

FIGURE 2 Fuzzy Inference System schematic.

(1) Defining linguistic term as input events (fuzzification), (2) Converting linguistic into fuzzy number, the method is utilized to aggregate multiple expert knowledge and experience, (3) Rule base for calculating the fuzzy number, (4) Defuzzification, converting aggregated fuzzy numbers into crisp probability value. Figure 2 shows the schematic of the fuzzy inference system. The fuzzy inference system are explained as follow.

The first module is fuzzification. Fuzzification is a process to convert the crisp value into a linguistic variable to make it compatible with the rule base. Input vector of FIS (crisp value) may be translated into linguistic terms, such as very high, high, moderate, low, very low. The linguistic terms can be shown as a membership function. The model of membership function depends on the expert knowledge, modeled problem, an input variable.

The second module is inference engine. An inference engine is a process of implication in reasoning input values to determine exit values as a form of decision making. Several inference engines have been applied in engineering applications. The most popular inference engine is Mamdani fuzzy model. The general "if-then rule form of the Mamdami algorithm is given in the following;

$$
\left(x_{1}=A_{i 1}\right) \wedge\left(X_{2}=A_{i 2}\right) \wedge\left(X_{r}=A_{i r}\right) \rightarrow y=B_{1}, \text { for } i=1,2, \ldots, k
$$

$X_{i}$ is the input variable, $A_{i r}$ and $B_{i}$ linguistic terms, $\mathrm{y}$ is the output variable, and k the number of rules.

The third module is rule base. The fuzzy sets applied to generate the fuzzy rules are defined by the database. The basic rule or rule base for fuzzy logic control is a form of "if-then" relation rules such as the following statement: "if $X=A$ " and "if $Y=B$ " then " $\mathrm{Z}=\mathrm{C}$ ". The fuzzy if-then rules are extracted from expert judgment, engineering knowledge, and experience 21.

The fourth module is defuzzification. Defuzzification is a process to transfer fuzzy sets into crisp value. Defuzzification has several methods in the literature of fuzzy. The centroid of Area (COA) is the popular method for the defuzzification process. The benefit of this method is all activated membership functions of the conclusion take part in the defuzzification process ${ }^{[2]}$. The COA method can be calculated using Eq. 4 .

$$
Z_{C O A}^{*}=\frac{\int_{Z} \mu_{A}(z) z d z}{\int_{Z} \mu_{A}(z) d z}
$$

The crisp value for "z" output and $\mu \mathrm{A}(\mathrm{z})$ is the aggregated output membership function.

In this paper, the linguistic term is scaled at five grades, e.g., very high $(\mathrm{VH})$, high $(\mathrm{H})$, medium $(\mathrm{M})$, low $(\mathrm{L})$, and very low $(\mathrm{VL})$. The fuzzy method is used to calculate the risk level of the hazards. Because of the uncertainty of the risk factors, a fuzzy inference system is used in this research.

$$
t a I=S i \sqrt{t+b}
$$




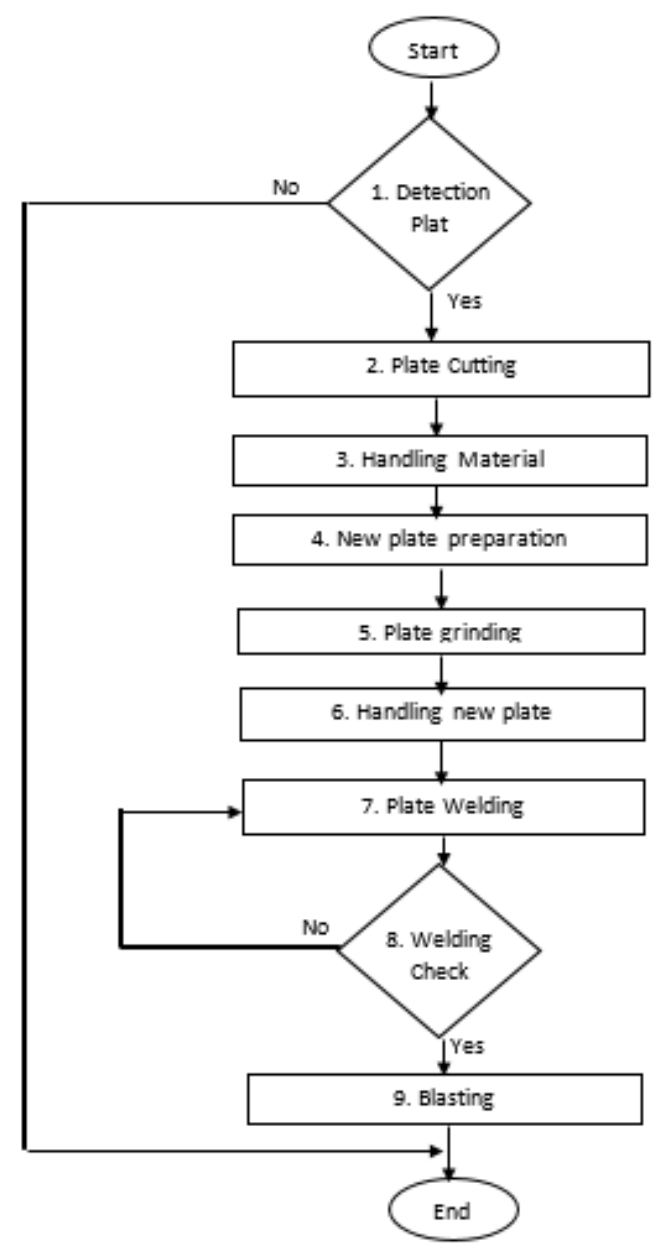

FIGURE 3 Replating activity procedures.

\section{3 | RESULTS AND DISCUSSION}

This chapter discusses the application of the methodology in Figure 1. It would be applied to ship maintenance especially replating activity. The main steps involve (1) risk identification using Job Safety analysis to find the hazards/causes. This process gives an output of likelihood, and consequences for the next process (2) Bayesian network modeling is used to calculate the probability of likelihood (3) risk assessment using fuzzy. inference system.

\section{1 | Risk identification}

Replating requires many things that should be considered to avoid delays in the schedule. The number of activities or sequence of work is a priority. If there is a problem in one of the replating activities, it would make the ship repair longer than planned. So, the replating procedures would need to identify the sub-activity of replating. The replating procedure can be shown in Figure 3. After that, Job Safety Analysis (JSA) is used to determine the hazard or risk of replicating activities. These activities are described in several sub-activities. Detailed JSA of maintenance operations is conducted, hazards factors in each operation step, and mitigation for each hazard factor. The JSA Replating activities on the ship repair process can be seen in Table 4 .

The data in Table 4 was acquired from discussion with the management of PT. PAL Indonesia (Persero). It discusses replicating activity, finds the hazards/causes of each sub-activity, the value for likelihood, and consequences. The value of likelihood is based on Table 1 and consequences based on Table 2 . The value consequences are only calculated for the occupational health and safety (OHS) factor. The plate-cutting sub-activity has four hazards/causes. For example, the explosion has a small likelihood, 
TABLE 4 JSA operating activity.

\begin{tabular}{|c|c|c|c|c|c|c|}
\hline \multirow[t]{2}{*}{$\#$} & \multirow[t]{2}{*}{ Sub Activity } & \multirow[t]{2}{*}{ Hazard/Cause } & \multicolumn{4}{|c|}{ Risk } \\
\hline & & & $\mathbf{L}$ & $\mathbf{C}$ & & RL \\
\hline 1 & Plate Detection & Equipment check failure & 2 & 1 & 2 & Low \\
\hline \multirow[t]{5}{*}{2} & Plate Cutting & Explosion & 2 & 4 & 8 & Medium \\
\hline & & Cutting Equipment failure & 2 & 3 & 6 & Medium \\
\hline & & Scaffolding broken & 2 & 3 & 6 & Medium \\
\hline & & Human error & 3 & 3 & 9 & Medium \\
\hline & & Bad weather & 3 & 3 & 9 & Medium \\
\hline \multirow[t]{3}{*}{3} & Handling Material & Crane failure & 2 & 4 & 8 & Medium \\
\hline & & Rigging failure & 2 & 3 & 6 & Medium \\
\hline & & Human Error & 4 & 3 & 12 & High \\
\hline \multirow[t]{2}{*}{4} & New plate preparation & No stock material & 3 & 1 & 3 & Low \\
\hline & & Cutting equipment failure & 2 & 4 & 8 & Medium \\
\hline \multirow[t]{2}{*}{5} & Grinding Plate & Grinding equipment failure & 2 & 3 & 6 & Medium \\
\hline & & Human Error & 3 & 3 & 9 & Medium \\
\hline \multirow[t]{3}{*}{6} & Handling new material & Crane failure & 2 & 3 & 6 & Medium \\
\hline & & Rigging failure & 2 & 3 & 6 & Medium \\
\hline & & Human Error & 3 & 3 & 9 & Medium \\
\hline \multirow[t]{5}{*}{7} & Welding Plate & Welding equipment failure & 1 & 2 & 2 & Low \\
\hline & & Low Welding quality & 1 & 2 & 2 & Low \\
\hline & & Inadequate protection & 2 & 3 & 6 & Medium \\
\hline & & Human error & 1 & 3 & 3 & Low \\
\hline & & Bad weather & 3 & 3 & 9 & Medium \\
\hline \multirow[t]{2}{*}{8} & Welding check & Equipment check failure & 2 & 2 & 4 & Medium \\
\hline & & Human error & 1 & 2 & 2 & Low \\
\hline \multirow[t]{5}{*}{9} & Blasting & Scaffolding failure & 2 & 3 & 6 & Medium \\
\hline & & Blasting equipment failure & 2 & 3 & 6 & Medium \\
\hline & & No paint material & 2 & 2 & 4 & Medium \\
\hline & & Human error & 1 & 3 & 3 & Low \\
\hline & & Bad weather & 3 & 3 & 9 & Medium \\
\hline
\end{tabular}

TABLE 5 Bayesian network codes.

\begin{tabular}{clllll}
\hline Code & \multicolumn{1}{c}{ Description } & Code & \multicolumn{1}{c}{ Description } & Code & \multicolumn{1}{c}{ Description } \\
\hline PD & Plate detection & H21 & Human error & E52 & Component damaged \\
PC & Plate Cutting & H22 & Fatigue employee & E53 & Armature damaged \\
HM & Handling material & H23 & Lack of job qualification & E54 & Carbon brush damage \\
NP & New plate preparation & B21 & Bad weather & E71 & Welding equipment failure \\
GP & Grinding the plate & B22 & Rainy & E72 & Low welding quality \\
HN & Handling new material & B23 & Strong wind & E73 & Inadequate protection \\
WP & Welding plate & E31 & Rigging failure & Welding gun failure \\
WC & Welding check & E32 & Crane failure & E75 & Wire feeder failure \\
BL & Blasting & E33 & Connection not fixed well & E76 & Control system failure \\
E11 & Equipment check failure & E34 & Rigging broken & E77 & Motor not function \\
E12 & No maintenance & E35 & Wrong rigging position & E78 & Wrong Setting control \\
E13 & Sensor Damaged & E36 & Motor crane failure & E79 & Bad wire quality \\
E21 & Explosion & E37 & Control failure & E80 & Not using protection \\
E22 & Cutting equipment failure & E38 & Electric component failure & E81 & Bad quality protection \\
E23 & Scaffolding failure & E39 & No Power & E91 & Blasting equipment failure \\
E24 & Hose leakage & E40 & Power off & E92 & Spray gun damaged \\
E25 & Gas regulator leakage & E41 & Cable broken & Compressor damaged \\
E26 & Nozzle broken & M41 & No material & & \\
E27 & Torch damage & M42 & No stock & & \\
E28 & Connection damage & M43 & Incorrect specification & & \\
E29 & Rigging Connection bad & M44 & Material comes late & & \\
E30 & Shock pipe damage & E51 & Grinding equipment failure & & \\
\hline
\end{tabular}

so the value is two, and the consequence has the mayor consequences, so the value is 4 . Based on Eq. 1 and Table 3, the risk level can be calculated.

$$
\begin{aligned}
R L & =L \times C \\
& =2 \times 4 \\
& =8
\end{aligned}
$$




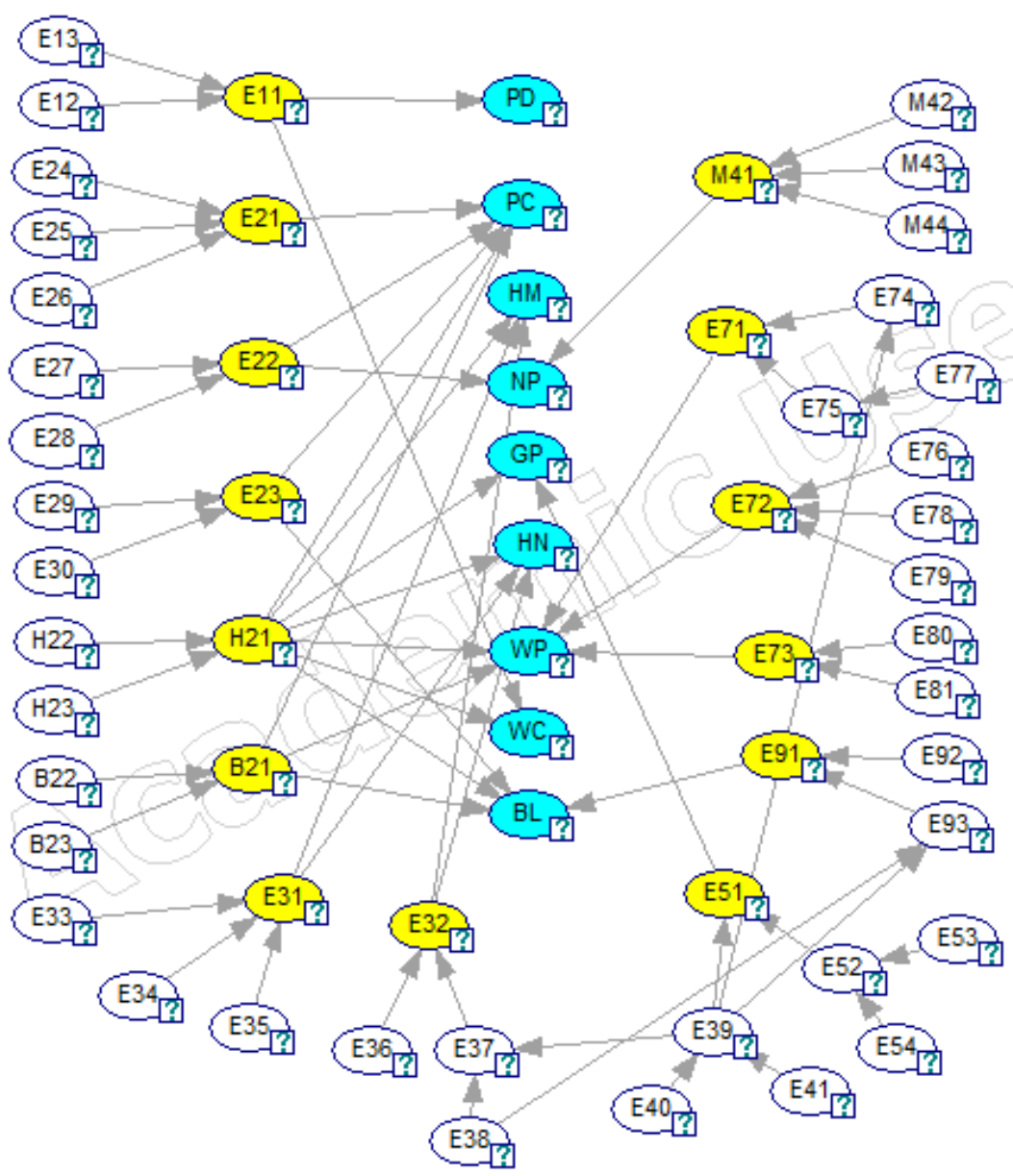

FIGURE 4 Bayesian network structure of replating activity.

So the risk level of explosion hazards/causes is eight or "medium" level.

\section{2 | Bayesian Network}

Bayesian Networks is utilized to carry out the likelihood modeling for replating activity. BN calculation for replating activities is carried out for each sub-activity. The calculation is used to find out the probability value of each sub-activity. To calculate the value of probability risk is done by determining the opportunity values in each sub-activity hazard. To calculate the value of probability risk is done by determining the opportunity values in each sub-activity hazard. This value is the result of a discussion with the expert. Bayesian network modeling is used to give information about the factors and the basic factor influence the likelihood factor. Overall Bayesian network structure or modeling can be shown in Figure 4. Each factor in the BN requires a code that is used to simplify forming the structure and calculating the likelihood probability. The code for each Sub-activity can be shown in Table 5 .

Bayesian network modeling uses to determine the Conditional Probability Table (CPT). The logical OR gate and experiencebased judgment were used to determine CPT in BN. Logical OR gate represent the deterministic relationship between father nodes and child nodes. For example, BN is a "Human error," if employees are fatigue and lack job qualification in a false (F) state, the human error should be in the false state. The CPT Bayesian network for human error factors shows in Table 6 . The values in Table 6 get from the expert's judgment based on their experience and knowledge. Five experts in the shipbuilding industry are invited to estimate the likelihood probability of these factors. Analytic hierarchy is utilized to determine the weight of five experts. The probability value is based on the likelihood factor level in Table 1 . The result of the likelihood probability from the expert can be shown in Table.3.4. 
TABLE 6 Bayesian network of human error factors.

\begin{tabular}{cccccc}
\hline $\begin{array}{l}\text { Fatigue Employee }(\mathbf{H 2 2}) \\
\mathbf{T = 0 . 6 5}\end{array}$ & $\mathbf{F = 0 . 3 6}$ & \multicolumn{2}{c}{ Lack of job qualification } & $(\mathbf{H 2 3})$ & \multicolumn{2}{c}{ Human Error $(\mathbf{H 2 1})$} \\
$\mathbf{T = 0 . 1 7}$ & $\mathbf{F = 0 . 8 3}$ & $\mathbf{T}$ & $\mathbf{F}$ \\
\hline $\mathrm{T}$ & & $\mathrm{T}$ & 0.72 & 0.28 \\
$\mathrm{~T}$ & & $\mathrm{~F}$ & 0.6 & 0.4 \\
$\mathrm{~F}$ & $\mathrm{~T}$ & 0.2 & 0.8 \\
$\mathrm{~F}$ & $\mathrm{~F}$ & 0.1 & 0.9 \\
\hline
\end{tabular}

TABLE 7 Bayesian network codes.

\begin{tabular}{clcccccc}
\hline$\#$ & \multicolumn{1}{c}{ Basic Factors } & Expert-1 & Expert-2 & Expert-3 & Expert-4 & Expert-5 & T \\
\hline 1 & No maintenance & 0.6 & 0.1 & 0.3 & 0.2 & 0.2 & 0.28 \\
2 & Sensor Damaged & 0.6 & 0.1 & 0.3 & 0.2 & 0.2 & 0.28 \\
3 & Hose leakage & 0.4 & 0.1 & 0.3 & 0.3 & 0.3 & 0.28 \\
4 & Gas regulator leakage & 0.3 & 0.1 & 0.3 & 0.2 & 0.2 & 0.22 \\
5 & Nozzle broken & 0.3 & 0.1 & 0.3 & 0.3 & 0.2 & 0.24 \\
6 & Torch damage & 0.2 & 0.1 & 0.1 & 0.08 & 0.6 & 0.22 \\
7 & Connection damage & 0.2 & 0.1 & 0.1 & 0.08 & 0.6 & 0.22 \\
8 & Rigging Connection bad & 0.2 & 0.1 & 0.1 & 0.08 & 0.5 & 0.20 \\
9 & Shock pipe damage & 0.2 & 0.1 & 0.1 & 0.08 & 0.5 & 0.20 \\
10 & Fatigue employee & 0.3 & 0.9 & 0.7 & 0.65 & 0.65 & 0.64 \\
11 & Lack of job qualification & 0.3 & 0.1 & 0.25 & 0.1 & 0.09 & 0.17 \\
12 & Rainy & 0.4 & 0.5 & 0.6 & 0.5 & 0.6 & 0.52 \\
13 & Strong wind & 0.1 & 0.1 & 0.1 & 0.07 & 0.07 & 0.09 \\
14 & Connection not fixed well & 0.4 & 0.1 & 0.35 & 0.1 & 0.7 & 0.33 \\
15 & Rigging broken & 0.4 & 0.1 & 0.4 & 0.3 & 0.7 & 0.38 \\
16 & Wrong rigging position & 0.4 & 0.1 & 0.3 & 0.3 & 0.7 & 0.36 \\
17 & Motor crane overload & 0.4 & 0.1 & 0.3 & 0.3 & 0.6 & 0.34 \\
18 & Electric component failure & 0.4 & 0.1 & 0.3 & 0.4 & 0.5 & 0.34 \\
19 & Power off & 0.4 & 0.1 & 0.3 & 0.2 & 0.6 & 0.32 \\
20 & Cable broken & 0.3 & 0.1 & 0.2 & 0.3 & 0.3 & 0.24 \\
21 & No stock & 0.6 & 0.6 & 0.4 & 0.4 & 0.7 & 0.54 \\
22 & Incorrect specification & 0.3 & 0.3 & 0.2 & 0.2 & 0.2 & 0.24 \\
23 & Material come late & 0.5 & 0.4 & 0.3 & 0.3 & 0.4 & 0.36 \\
24 & Armature damaged & 0.4 & 0.1 & 0.4 & 0.5 & 0.3 & 0.34 \\
25 & Carbon brush damaged & 0.6 & 0.1 & 0.6 & 0.6 & 0.4 & 0.46 \\
26 & Motor not function & 0.2 & 0.1 & 0.1 & 0.04 & 0.2 & 0.13 \\
27 & Incorrect setting parameter & 0.3 & 0.1 & 0.1 & 0.06 & 0.1 & 0.13 \\
28 & Bad wire quality & 0.2 & 0.1 & 0.1 & 0.06 & 0.1 & 0.11 \\
29 & Not using protection & 0.6 & 0.1 & 0.4 & 0.6 & 0.3 & 0.40 \\
30 & Bad quality protection & 0.4 & 0.1 & 0.4 & 0.4 & 0.1 & 0.28 \\
31 & Spray gun damaged & 0.3 & 0.1 & 0.1 & 0.05 & 0.6 & 0.23 \\
32 & Compressor damaged & 0.3 & 0.1 & 0.1 & 0.05 & 0.5 & 0.20 \\
\hline & & & & & & &
\end{tabular}

The likelihood of replating activity could be divided or classified into four factors, i.e., human error, equipment failure, no material, and bad weather. The equipment failure could be divided based on the sub-activity. The equipment failure consists of detection equipment, crane failure, rigging failure, cutting equipment, welding equipment, personal protective equipment (PPE), and blasting equipment. Every factor of equipment failure has the basic factors. For example, basic factors of crane failure are motor overload and control failure. The control failure has a basic factor, i.e., electric component failure and no power.

Bad weather conditions adverse impact on replating activity. This factor could be calculated due to the phenomenon of the environment. Two basic factors are structured as the parent nodes, whereas rainy and strong wind. The factor of no material condition conditions may reduce the probability of the entire operation. Due to the availability of material become the important factor of the operation. No material condition has four basic factors as the parent's nodes, whereas no stock material, incorrect specification, and material delay.

The nodes of likelihood factors are linked to the nodes of sub-activity of replating activity. The CPTs from the expert experience for the nodes of each factor are assigned according to the actual reasoning relationship among them. Table 7 showed the value of basic factors from the expert experience and knowledge. The calculation of likelihood probability based on Table 7 was calculated using the software. Note that the calculation BN models in this paper are developed using GeNIe software. To ensure the software calculation, the manual calculation is used to check the result of the software calculation. The manual calculation 


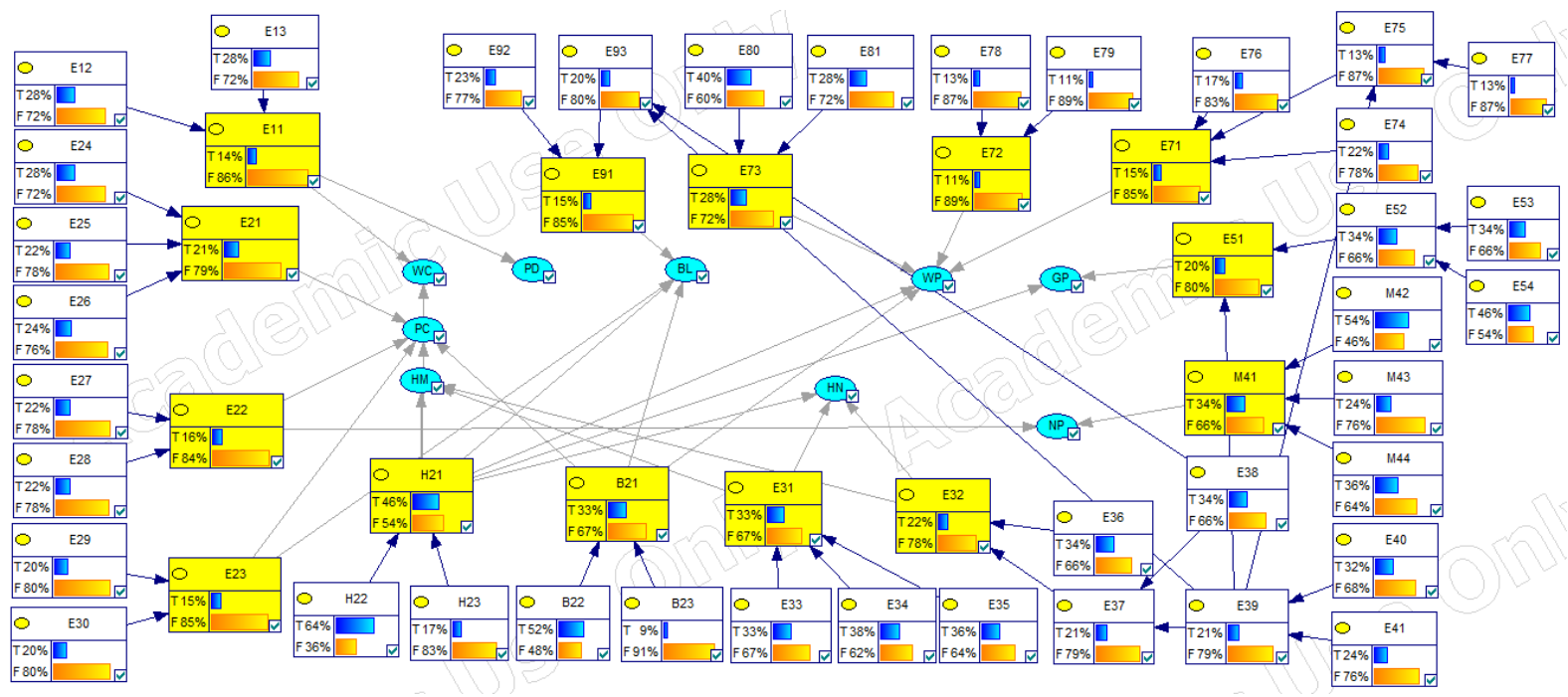

FIGURE 5 Bayesian network for replating activity.

of "Human Error" hazards/causes were calculated for the example calculation. The data of probability "Human Error" get from Table 6. The example calculation as follow:

$$
\begin{aligned}
P T T T & =P(H 21=T, H 22=T, H 23=T) \\
& =P(H 21=T \mid H 22=T, H 23=T) P(H 22=T) P(H 23=T) \\
& =0.72 \times 0.64 x 0.17 \\
& =0.08 \\
P T F T & =P(H 21=T, H 22=F, H 23=T) \\
& =P(H 21=T \mid H 22=F, H 23=T) P(H 22=F) P(H 23=T) \\
& =0.18 x 0.36 x 0.17 \\
& =0.01 \quad \\
P T F F & =P(H 21=T, H 22=F, H 23=F) \\
& =P(H 21=T \mid H 22=F, H 23=F) P(H 22=F) P(H 23=F) \\
& =0.1 \times 0.36 x 0.83 \\
& =0.03 \quad=0.46 \\
P T T F & =P(H 21=T, H 22=T, H 23=F) \\
& =P(H 21=T \mid H 22=T, H 23=T) P(H 22=T) P(H 23=F) \\
& =0.65 x 0.64 x 0.83 \\
& =0.35 \quad=0.08+0.01+0.03+0.35 \\
P( & H 21, H 22, H 23)=P T T T+P T F T+P T F F+P T T F
\end{aligned}
$$

From the manual calculation, the probability of Human Error (H21) is 0.46. Based on Figure 5, the probability of Human error using GeNIe software calculation is 0.46 . So, this comparison method gives the same result for the probability of human error. The next calculation of probability used the GeNIe software. Figure 5 explains the complete probability of likelihood for replating activity using GeNIe software. The value of probability could be used for the next process. 


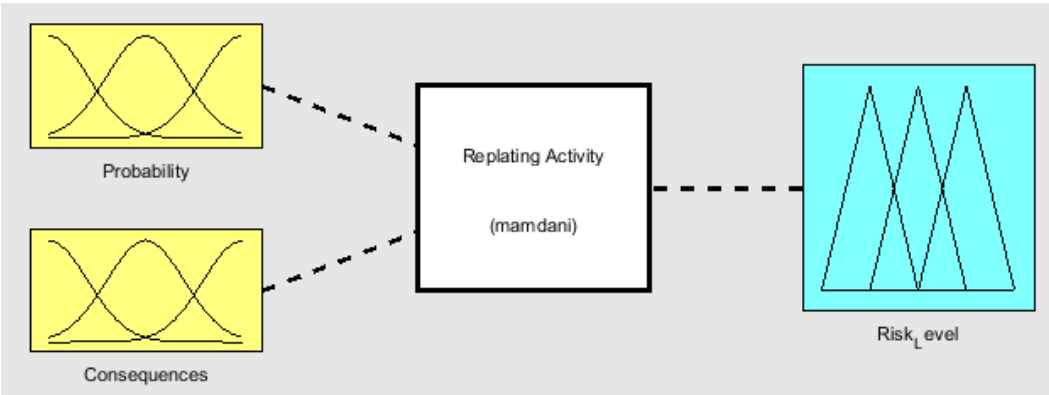

FIGURE 6 Structure for fuzzy replating.
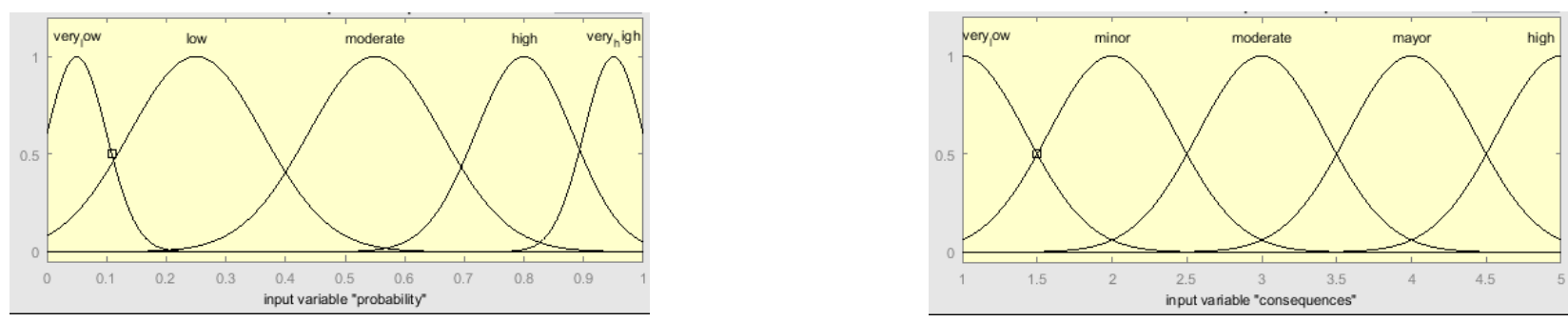

(a) (i)

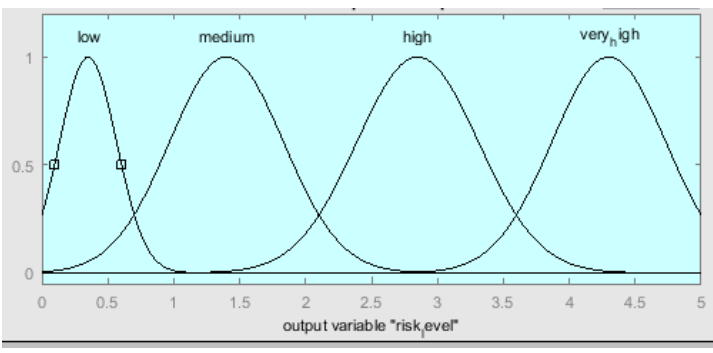

(b) (ii)

(c) (iii)

FIGURE 7 Membership input and output variables; (i) probability input (ii) consequences input (iii) risk level.

\section{3 | Risk Assessment using Fuzzy Inference System}

Risk assessment for this research uses the fuzzy inference method. The fuzzy has two inputs, i.e., probability of likelihood that has been calculated using GeNIe software and consequences from AJS table. The probability category of likelihood is scaled at five grades, e.g., very high $(\mathrm{VH})$ with value $0.9-1$, high $(\mathrm{H})$ with value $0.7-0.9$, moderate $(\mathrm{M})$ with value $0.4-0.7$, low (L) with the value of $0.1-0.4$, and very low (VL) with a value less than 0.1 . The consequences are scaled at five grades, these grades based on Table 1. The input and output structure of the risk assessment can be seen in Figure 6.

Input variable and output variables are shown in Figure 7. The variable is using the Gaussian membership function. It is used because of the more natural and closer to the reality of the function ${ }^{[23]}$. The Gaussian membership function can be represented:

$$
\operatorname{Gausian}(x, c, \tau)=e^{\frac{-1}{2}\left(\frac{x-c}{\tau}\right)^{2}}
$$

Where $\mathrm{c}$ is the center and $\sigma$ is the width of the membership function. The next step is to make fuzzy rules called base rules. Rules are made to represent relationships between variable inputs and output based on knowledge and field data. The following is an example of a rule base below:

- If (Probability is very low) and (Consequences is very low) then (Risk level is low)

- If (Probability is very low) and (Consequences is low) then (Risk level is low) 


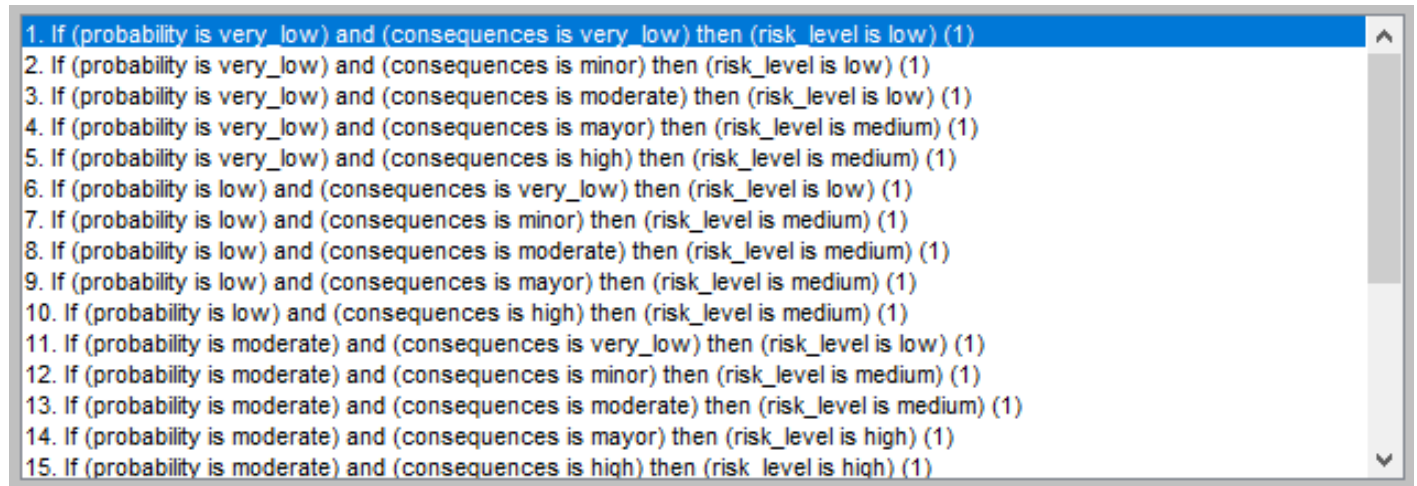

FIGURE 8 Rule base fuzzy.

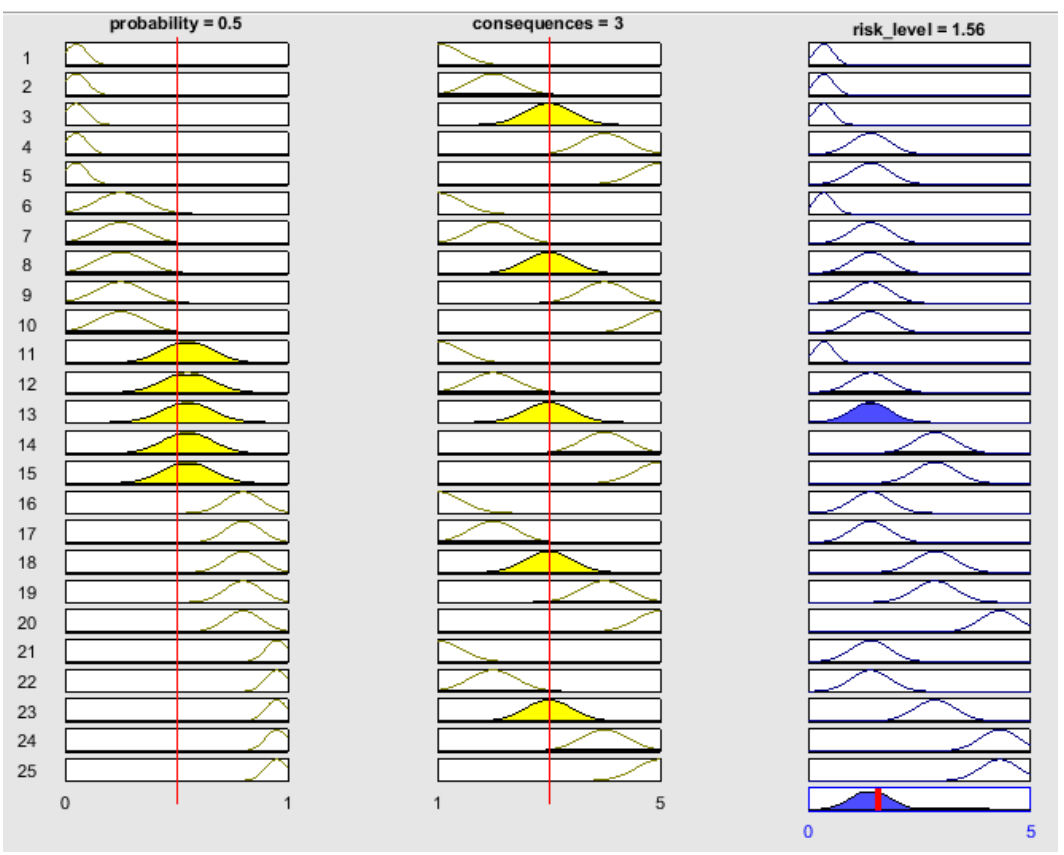

FIGURE 9 Graphical indication of the fuzzy mechanism.

- If (Probability is medium) and (Consequences is mayor) then (Risk level is high)

- If (Probability is high) and (Consequences is very low) then (Risk level is medium)

The total rule-based for this risk assessment is 25 rule bases. Figure 8 showed the rule base for the fuzzy calculation.

\section{4 | Risk Level}

The risk level of replating activity was calculated automatically using the software. This software calculation is shown in Figure 9. This graphical indication gives easy information for risk level assessment. The calculation is by changing the red line of probability and consequences input. The risk level was automatically calculated, and it can be shown on the third picture of the risk level. One example to uses this software calculation is determining the risk level of "human error" hazards or causes on "Handling material" sub-activities.

Based on Table 8 , the probability of likelihood value is 0.46 , and based on Table 4 , the consequences value is 3 (three). We have to change the red line probability line into value 0.46 , and the consequences line into value 3 . After the input has been entered, 
TABLE 8 The output of proposed method.

\begin{tabular}{|c|c|c|c|c|c|c|}
\hline \multirow[t]{2}{*}{$\#$} & \multirow[t]{2}{*}{ Sub Activity } & \multirow[t]{2}{*}{ Hazard } & \multicolumn{4}{|c|}{ Risk Assessment } \\
\hline & & & $\mathbf{L}$ & $\mathbf{C}$ & & $\mathbf{L}$ \\
\hline 1 & Plate Detection & Equipment check failure & 0.14 & 1 & 0.65 & Low \\
\hline \multirow[t]{5}{*}{2} & Plate Cutting & Explosion & 0.21 & 4 & 1.43 & Medium \\
\hline & & Cutting Equipment failure & 0.16 & 3 & 1.37 & Medium \\
\hline & & Scaffolding broken & 0.15 & 3 & 1.34 & Medium \\
\hline & & Human error & 0.38 & 3 & 1.61 & Medium \\
\hline & & Bad weather & 0.33 & 3 & 1.57 & Medium \\
\hline \multirow[t]{3}{*}{3} & Handling Material & Crane failure & 0.22 & 4 & 1.44 & Medium \\
\hline & & Rigging failure & 0.33 & 3 & 1.57 & Medium \\
\hline & & Human Error & 0.46 & 3 & 1.58 & Medium \\
\hline \multirow[t]{2}{*}{4} & New plate preparation & No stock material & 0.34 & 1 & 0.63 & Low \\
\hline & & Cutting equipment failure & 0.16 & 4 & 1.39 & Medium \\
\hline \multirow[t]{2}{*}{5} & Grinding Plate & Grinding equipment failure & 0.20 & 3 & 1.42 & Medium \\
\hline & & Human Error & 0.46 & 3 & 1.58 & Medium \\
\hline \multirow[t]{3}{*}{6} & Handling new material & Crane failure & 0.22 & 3 & 1.44 & Medium \\
\hline & & Rigging failure & 0.33 & 3 & 1.57 & Medium \\
\hline & & Human Error & 0.46 & 3 & 1.58 & Medium \\
\hline \multirow[t]{5}{*}{7} & Welding Plate & Welding equipment failure & 0.15 & 2 & 1.34 & Medium \\
\hline & & Low Welding quality & 0.11 & 2 & 1.10 & Medium \\
\hline & & Inadequate protection & 0.28 & 3 & 1.54 & Medium \\
\hline & & Human error & 0.46 & 3 & 1.58 & Medium \\
\hline & & Bad weather & 0.33 & 3 & 1.57 & Medium \\
\hline \multirow[t]{2}{*}{8} & Welding check & Equipment check failure & 0.14 & 2 & 1.29 & Medium \\
\hline & & Human error & 0.46 & 2 & 1.38 & Medium \\
\hline \multirow[t]{5}{*}{9} & Blasting & Scaffolding failure & 0.15 & 3 & 1.34 & Medium \\
\hline & & Blasting equipment failure & 0.15 & 3 & 1.34 & Medium \\
\hline & & No paint material & 0.34 & 2 & 1.38 & Medium \\
\hline & & Human error & 0.46 & 3 & 1.58 & Medium \\
\hline & & Bad weather & 0.33 & 3 & 1.57 & Medium \\
\hline
\end{tabular}

the risk level was automatically calculated. The output risk level is giving a value of 1.58 . This is mean that the risk level of human error hazards on "Handling material" has a "Medium" level. According to the example, risk level calculation using fuzzy, the resulting risk level is present in Table 8 .

The interdependency of input and output parameters derived from the rules can be shown in Figure 10. It gives a new risk matrix for risk assessment. The benefit of this new risk matrix is that the uncertainty area would be covered. On the other hand, the new risk matrix is better than the traditional risk matrix.

\section{5 | Comparison of the risk level}

The risk level on Table 4 (traditional method) was compared to Table 8 (proposed model) to complete the research. From these two methods, the likelihood input from both methods is different. The traditional method is given from PT. Pal Indonesia (Persero) and the proposed model are given by discussion with the expert from the shipyard company. The value of occupational health and safety (OHS) consequences is the same, so it is no different in the value. Table 9 showed the comparison of the two methods for calculating risk level. The first method based on Table 4 has one high-risk level on the basic factor of human error (handling material sub-activity). The value of Likelihood (L) of this basic factor is four, and the consequences (C) value is 3 .

So, the risk level is 12 or high. This is different from the proposed model after calculating all the risk levels. The proposed model has a medium level for human error (handling material). The difference in the risk level happens because the proposed model calculates the basic factors of the hazards/causes. It calculated using the probability of each basic factor based on the experience and knowledge of an expert. Because of that, the risk level of "Human Error (handling material)" decreases until Medium level. It means that the hazards still in a safe condition. The other results change from the low level into the medium level. The reason is the same as the explanation before. As a result, the calculation of the first method calculation may be inaccurate in real-life problems. The proposed model takes value from the experience and knowledge of experts. The value from the expert becomes relative importance among the variables.

Based on the risk analysis result of the proposed model, ship maintenance operations can be well prepared and systematized to enrich the overall safety. Therefore, the output of the proposed model for ship maintenance risk assessment, especially on replating activity, is more sure and accurate. 


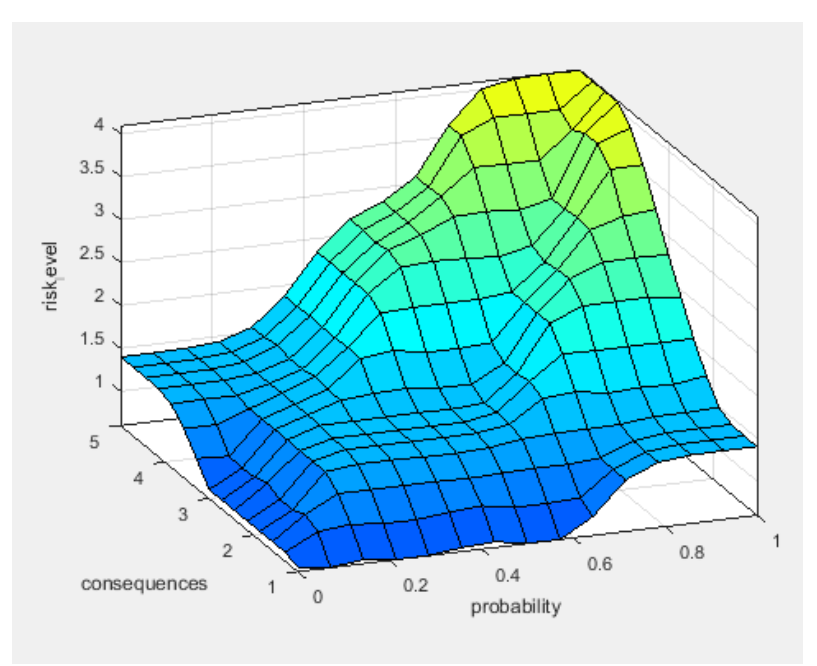

FIGURE 10 Control surface of risk assessment.

TABLE 9 The output of proposed method.

\begin{tabular}{|c|c|c|c|c|}
\hline \multirow[t]{3}{*}{ Hazards/Cause } & \multicolumn{4}{|c|}{ Risk Level } \\
\hline & \multicolumn{2}{|c|}{ Traditional Method } & \multicolumn{2}{|c|}{ Proposed Method } \\
\hline & Value & Level & Value & Level \\
\hline Equipment check failure & 4 & Low & 0.649 & Low \\
\hline Explosion & 8 & Medium & 1.4 & Medium \\
\hline Cutting Equipment failure & 6 & Medium & 1.4 & Medium \\
\hline Scaffolding broken & 6 & Medium & 1.4 & Medium \\
\hline Human error & 9 & Medium & 1.4 & Medium \\
\hline Bad weather & 9 & Medium & 1.4 & Medium \\
\hline Crane failure & 8 & Medium & 1.4 & Medium \\
\hline Rigging failure & 6 & Medium & 1.4 & Medium \\
\hline Human Error & 12 & High & 1.64 & Medium \\
\hline No stock material & 3 & Low & 0.638 & Low \\
\hline Cutting equipment failure & 8 & Medium & 1.4 & Medium \\
\hline Grinding equipment failure & 6 & Medium & 1.4 & Medium \\
\hline Human Error & 9 & Medium & 1.64 & Medium \\
\hline Crane failure & 6 & Medium & 1.4 & Medium \\
\hline Rigging failure & 6 & Medium & 1.4 & Medium \\
\hline Human Error & 9 & Medium & 1.64 & Medium \\
\hline Welding equipment failure & 2 & Low & 1.3 & Medium \\
\hline Low Welding quality & 2 & Low & 1.07 & Medium \\
\hline Inadequate protection & 6 & Medium & 1.4 & Medium \\
\hline Human error & 3 & Low & 1.64 & Medium \\
\hline Bad weather & 9 & Medium & 1.4 & Medium \\
\hline Equipment check failure & 4 & Medium & 1.28 & Medium \\
\hline Human error & 2 & Low & 1.31 & Medium \\
\hline Scaffolding failure & 6 & Medium & 1.4 & Medium \\
\hline Blasting equipment failure & 6 & Medium & 1.4 & Medium \\
\hline No paint material & 4 & Medium & 1.31 & Medium \\
\hline Human error & 3 & Low & 1.64 & Medium \\
\hline Bad weather & 9 & Medium & 1.4 & Medium \\
\hline
\end{tabular}

\section{4 | CONCLUSION}

In this research, an integrated methodology of Job Safety Analysis (JSA) and fuzzy inference system for calculating the risk level of replating hazards is proposed. The calculation of the risk level is the combination of the Bayesian Networks (BN) and quantitative (fuzzy inference system) technique. The input probability gets from discussion with the expert. This discussion to find out the values of the basic factors of the likelihood and the probability. The result of the proposed model gets the different risk levels of replating. In the proposed model does not have a risk level with the criteria "high level." The other risk level changes from "low level" into "medium level." This happens due to the probability calculation for each basic factor. The value 
gets from the expert give impact the calculation of risk level. It makes the probability likelihood value bigger than the likelihood value (traditional method). So, it gives a different result for several hazards/causes.

From the observations, the proposed method can be an alternative method for risk analysis on ship maintenance operations, especially on replating activity. It can help to manage the risk factors related to the activation process and unexpected incidents. Based on the analysis result, replating activity can be well prepared and systematized to achieve zero accident and reliability operations. The output of the proposed model is more accurate, precise. The relationship of the input (probability of likelihood and consequences) and output is more flexible and realistic based on experience and knowledge. This proposed model has a wide application for another operation.

\section{5 | ACKNOWLEDGMENT}

The author gratefully acknowledges the data provided by PT. PAL Indonesia (persero) and the BayesFusion, LLC for the GeNIe software licenses.

\section{References}

1. Barlas B. Shipyard fatalities in Turkey. Safety Science 2012;50(5):1247-1252.

2. Basuki M, Artana KB, Nugroho S, Dinariyana AAB. Shipbuilding Industry in Indonesia, a Risk Perspective (in Indonesia). In: Proceedings of national Seminar of Postgraduate study Surabaya: Institut Teknologi Sepuluh Nopember Surabaya; 2010. p. $1-6$.

3. Jamshidi A, Yazdani-Chamzini A, Yakhchali SH, Khaleghi S. Developing a new fuzzy inference system for pipeline risk assessment. Journal of Loss Prevention in the Process Industries 2013;26(1):197-208.

4. Chao EL, Henshaw JL. Job Hazard Analysis. OSHA Publication 30712002 (Revised), Occupational Safety and Health Administration. In: Job Hazard Analysis, vol. 29 Washington: US Department of Labor; 2002.p. 1-21.

5. Holt ASJ. Principles of Construction Safety. London: Blackwell Science; 2011.

6. Santoso B. Perbandingan Pendekantan Muhlbauer dan Fuzzy Inference System Pada Proses Penilaian Resiko: Studi kasus Pipa Bawah Laut 14" PHE-WMO. PhD thesis, Institut Teknologi Sepuluh Nopember Surabaya; 2014.

7. Friis-Hansen P, Simonsen BC. GRACAT: software for grounding and collision risk analysis. Marine Structures 2002;15(45):383-401.

8. Medina Oliva G, Weber P, Simon C, Iung B. Bayesian networks applications on dependability, risk analysis and maintenance. 2nd IFAC Workshop on Dependable Control of Discrete System 2009;2:245-250.

9. Kurniawan A, Santoso M, Dhani MR. Identifikasi Bahaya Pada Pekerjaan Maintenance Kapal Menggunakan Metode HIRARC dan FTA Dengan Pendekatan Fuzzy di Industri Kapal. In: Proceeding 1st Conference on Safety Engineering and Its Application Surabaya, Indonesia: Politeknik Perkapalan Negeri Surabaya; 2017. p. 182-186.

10. Oktavia CA, Maulidi R. Penerapan Logika Fuzzy Sugeno untuk Penenuan Reward pada Game Edukasi Aku Bisa. JUTI: Jurnal Ilmiah Teknologi Informasi 2019 aug;17(2):117-124.

11. Farosanti L, Fatichah C. Perbaikan Segmentasi Pembuluh Darah Tipis Pada Citra Retina Menggunakan Fuzzy Entropy. JUTI: Jurnal Ilmiah Teknologi Informasi 2019 aug;17(2):135.

12. Administration OS, Health. Job Hazard Analysis. Washington: US Department of Labor; 2002.

13. Swartz G. Job Hazard Analysis - a primer on identifying and controlling hazards. Professional Safety 2002;47(11):27-33.

14. Raveggi F, Mazzetti S. Job Safety Analysis as a mean to increase safety awareness and achieve sustainable improvements in safety performance. Chemical Engineering Transactions 2010;19:421-425. 
15. Pearl J. Probabilistic Reasoning in Intelligent Systems. San Francisco, CA: Morgan Kauffman; 1975.

16. Wang ZZ, Chen C. Fuzzy comprehensive Bayesian network-based safety risk assessment for metro construction projects. Tunnelling and Underground Space Technology 2017;70:330-342.

17. Nguyen LD, Tran DQ, Chandrawinata MP. Predicting safety risk of working at heights using bayesian networks. Journal of Construction Engineering and Management 2016;142(9):040-16041.

18. Murphy kP. Dynamic Bayesian Networks: Representation, Inference and Learning. PhD thesis, University of California, Berkeley; 2002.

19. Wang Y, Li L, Chang M, Chen H, Dong X, Ren Y, et al. Fault Diagnosis Expert System Based on Integration of FaultTree and Neural Network. In: Proceedings - 2009 International Conference on Computational Intelligence and Software Engineering, CiSE 2009 IEEE; 2009. p. 1-4.

20. Jaderi F, Ibrahim ZZ, Zahiri MR. Criticality analysis of petrochemical assets using risk based maintenance and the fuzzy inference system. Process Safety and Environmental Protection 2019;121:312-325.

21. Ghaseni E, Ataei M. Application of fuzzy logic for predicting roof fall rate in coal mines. Neural Comput \& Applic 2013;22(1):S311-S321.

22. Daftaribesheli A, Ataei M, Sereshki F. Assessment of rock slope stability using the Fuzzy Slope Mass Rating (FSMR) system Abbas. Applied Soft Computing Journal 2011;11(8):4465-4473.

23. Markowski AS, Mannan MS. Fuzzy logic for piping risk assessment (pfLOPA). Journal of Loss Prevention in the Process Industries 2009;22(6):921-927.

How to cite this article: Nugroho C.W., Pitana T., Dinariyana B., (2020), Risk Analysis Using Job Safety Analysis-Fuzzy Integration for Ship Maintenance Operation, IPTEK The Journal of Technology and Science, 31(3):327-342. 